\title{
The control of venereal disease
}

\author{
J. W. R. HARRIS \\ St. Giles' Hospital, London SE5 7RN
}

The recent dramatic increase in the transmission of venereal disease is not an isolated social phenomenon but is one manifestation of the alteration in the behaviour of society during the last decade (Guthe and Willcox, 1971). Behaviour patterns vary in different social and ethnic groups and are greatly altered by environmental pressures. Any consideration of the difficulties associated with locating a patient with infection must be related to the medical and social conditions which exist in his area at the time. Failure to locate the patient with infection may be due to factors inherent in the patient himself, in his environment, or in the control system.

In some countries the evolutionary process of medicine segregated patients with venereal diseases in special clinics. This was undoubtedly the result of the social implications of such diseases (Brain, 1964). Geographical separation of the clinics from other branches of medicine encouraged professional isolation. Secrecy bred fear and ignorance in the lay public. This is still the cultural environment of some of our medical colleagues. When one considers the individual patient, one must always remember that he will reflect his environment in both knowledge and behaviour.

The patient who has venereal disease may be unaware of his infection. This may be because his infection is asymptomatic (Pariser, Farmer, and Marino, 1964) (a more common occurrence in women than in men and in the homosexual than in the heterosexual). It may also be that he does not relate his symptoms to the probability of sexually transmitted disease. This is easily understood when one considers that his main symptom could be that of pharyngitis (Owen and Hill, 1972), a cutaneous rash, or genital pruritus. It could also be due to his not having been instructed in the symptomatology of venereal disease.

Although aware of the possible nature of his infection, the potential patient may be frightened to attend the public clinic because he fears the social

A paper specially commended by the judges of the entries for The International Health Foundation Award, 1973 consequences which he believes are associated with therapy. The geographical siting of the clinic may unfortunately be such that he feels exposed to the public gaze as he enters and leaves the building. Rumours may abound of 'cluster' contact tracing and he may feel that such investigations would nullify any other attempts to guarantee anonymity. $\mathrm{He}$ may be ill-informed about the methods of treatment and be afraid of his own warped concepts of such therapy. His cultural background may be such that he views free treatment as a poor and inadequate substitute for the therapy received from one's own private doctor. In some societies there is a belief that privacy can only be guaranteed on a fee-paying basis (Willcox, 1970). In others the individual may choose to consult quacks, witch doctors, herbalists, and other exponents of traditional and fringe medicine before attending the government clinic as a last resort (Lomholt, 1968).

Many, and indeed all, of the factors mentioned above can be altered by suitable health education designed for the society towards which it is directed. The attitudes of the individual and the society can be modified gradually while the understanding of the nature of venereal diseases and of their modern treatment and control will do much to dispel the stigma which feeds on ignorance and fear.

Unfortunately, the infected individual may belong to the small but important group who do not feel sufficiently motivated to attend for examination. This irresponsible attitude both to their own health and to that of others is a sad reflection of our society. One can understand such behaviour from those with low intelligence or marked psychopathic traits and drug addicts, but it is depressing to see it masquerading under the guise of sexual freedom.

The major environmental factor in the location of the patient is the nature and quality of the diagnostic, therapeutic, and contact tracing facilities available for the management of sexually-transmitted disease. However, these facilities are financed by society in general and the attitudes of the society will determine the type and quality of the control which it feels to 
be justifiable. The ready availability rather than the mere presence of funds can be a determinant factor in this matter. Frequently the community is unable to escape from its own cultural and religious heritage. The sense of urgency in the community will be a function of disease priority. It would be more difficult to engender a sense of urgency in relation to venereal disease in a developing country which has monumental problems of overpopulation, malnutrition, tuberculosis, and high maternal and infant mortality and morbidity rates. Even if there is an earnest desire to combat venereal disease in such an environment, there will rarely be sufficient money or personnel to carry the project through.

The developmental status of a community may render western control methods totally unsuitable. Polygamy presents a definite challenge to western style contact tracing. The status of women may be so different that the entire concept of treating the two sexes in a unit relationship has to be completely altered. If a male doctor cannot examine females and a female doctor cannot examine males, medical correlation and communication are impoverished. Who will contact trace in such circumstances ?

The geographical siting of the area has an ppreciaable effect on the local infection rate and the ease of locating individuals. Obviously the incidence of infection is much higher in metropolitan areas, ports, and major tourist centres, where there is a large floating population. 'Birds of passage' such as these are extremely difficult to find. In rural areas infection rates will be much lower, but if they become too low the physician will obtain insufficient clinical experience and will be starved of the clinical stimulus one derives from colleagues. There will be the contact tracing difficulties prevalent in 'closed' communities and he will have to contend with dubious laboratory facilities.

Health education has enormous potential as the method to reduce the significance of these patient factors. However, health education is a two-edged sword and if used incorrectly will cause unhealthy degrees of anxiety, as was noted by Kite and Grimble (1963). In 1962 the World Forum on Syphilis and Other Treponematoses included a section on behavioural science in the field of venereal disease control. A Behavioural Sciences Section was set up in 1963 as an integral part of the United States Public Health Service (Forer, 1965). Numerous baseline studies were carried out to ascertain the associations between knowledge, attitudes, and behaviour in different parts of the world. Both long-range programmes (Rowntree, 1966) and short-duration intensive campaigns (American Social Health Association, 1968) have been undertaken.

Starck-Romanus (1973) noted a marked reduction in the gonorrhoea rate in Sweden during and after a non-authoritarian campaign using posters and television commercials to advocate the use of condoms.

Education is still a relatively new weapon but one which must be developed as quickly as possible in the context of the local situation. This might best be supervised on a global basis by some international body using the facilities of the various university faculties in different countries.

The unfortunate attitude of certain factions of the medical profession towards venereology has already been mentioned. This is probably cultural in origin and will undoubtedly pass with time. However, a much more serious aspect is the lack of awareness on the part of many doctors of the extragenital manifestations of venereal disease (Harris, McCann, and Mahony, 1973). Webster (1970), who investigated the quality of the professional education about venereal disease in medical schools throughout the world, found that their public health, epidemiological and sociological ramifications received scant attention. When one considers that McKenzie-Pollock (1970) noted that 80 per cent. of patients with syphilis in the U.S.A. were receiving treatment in the private sector it is clear that there is a great need for improvement in the nature and quality of medical education.

Efficient contact tracing does help to locate the patient. It must be executed without loss of time but must still preserve confidentiality. The value of 'cluster' techniques is debatable. This method, which involves the testing of social as well as sexual contacts, inevitably reduces the patient's feeling of security and may explain the failure of the contact tracing system as outlined by Brown (1970). Willcox (1966) noted that primary source and secondary promiscuous contacts are the most difficult to locate and referred to the 'feedback' mechanism by which there is continual renewal of the pool of occult gonorrhoea in females with associated maintenance of high infection rates. Morton (1972) noted that nowadays a higher percentage of infected patients know their source contact and that the mechanics of contact tracing are easier than ever before.

With increasing population movement either on holiday or business and the associated ease of travel, international contact tracing is becoming increasingly important. Elste (1968) has described the exchange of contact data between European countries. A number of countries have established international contact tracing bureaux. At a recent meeting in Copenhagen under the auspices of the W.H.O. (Brit. F. vener. Dis. (1973), 49, 89) steps were taken to improve international contact tracing.

It is impossible to discuss contact tracing without mentioning the controversy that has existed for some years in the U.S.A. about treatment in the private sector. There will always be some patients who desire to be treated on a fee-paying basis and this is undoubtedly their privilege. The onus is on the physician who undertakes such treatment to attempt to obtain 
contact data and either to act upon it himself or pass it on to the national service. Co-operation rather than competition must be the keynote of success.

Unfortunately contact tracing has great limitations when applied to the 'high risk' groups of patients. These are those patients who have a high promiscuity index and associated high infection and re-infection rates. Because of this they require special attention from the clinician and the epidemiologist. Hermans and de Cock (1965) reviewed the importance of the homosexual in the transmission of venereal disease in Holland. Jefferiss (1966) reiterated the importance of the sympathetic handling of these patients. They not only have a high infection rate with syphilis but are also subject to high infection rates with hepatitis B (Jeffries, James, Jefferiss, MacLeod, and Willcox, 1973).

Willcox, Jefferiss, and Naughten (1966) discussed the high gonorrhoea morbidity rate among immigrants in the United Kingdom and it is relevant to note that, with increasing population movements in search of work in the Europe of the seventies, this problem will become more intense. The single heterosexual male in a strange environment is more likely to be promiscuous than when he is in his own community. Tourists and seamen (Idsøe and Guthe, 1967) will behave in a similar manner. These three problem groups can only be managed on an international basis by ensuring that they can easily obtain the free treatment to which they are entitled. Also they should fully understand the potential hazards of their transient liasions. Simple facts such as noting the name and address of each contact would greatly facilitate contact tracing if the need arose.

Prostitution still flourishes in society although it is now illegal in many countries. Health education of prostitutes is essential, and regular screening accompanied by epidemiological treatment may help to control the infection rate (de Amorim, 1966).

In countries where there are high incidences of infection, screening methods have a valuable place in the control of disease. Dandoy and McKenna (1964) showed the value of serological screening for syphilis in the U.S.A. and Mellone and Pagenotto (1965) demonstrated its use in Brazil. Screening for the presence of gonococcal infection among asymptomatic females by specimens for culture from the cervix and the rectum was reported by Hart (1971). These techniques will be applicable in many countries in the world. One may hope that the process will be extended so that any patient presenting to a physician with evidence of one sexually-transmitted disease is automatically screened for all the other infections. Again, a patient in one of the high risk groups, e.g. a homosexual presenting to a psychiatric clinic, would be screened for syphilis, gonorrhoea, and hepatitis B.

It is difficult to explain to patients who have been in contact with a venereal disease and have summoned up the courage to attend a clinic that they should not be treated until the infecting organism is isolated. Frequently, in developed countries, one can explain the rationale behind this, but in conditions where there is an enormous work load and inadequate diagnostic facilities and the patients are unable to understand such reasoning, there is a definite place for epidemiological treatment. Willcox (1950) noted this in the treatment of genital sores in East Africa. The question of epidemiological therapy is still controversial.

A widespread clinical service providing modern diagnostic and therapeutic facilities will increase the patient's faith in the doctor's management and encourage him to attend for treatment. Undue emphasis on contact tracing and health education by such a service is ill advised (Report of the National Commission on V.D., 1972). One could dispute whether resources spent in the U.S.A. on contact tracing could not be better employed in establishing a widespread clinical service of high quality. The American experience would appear to substantiate this. At the same time, it is important to remember that in many countries the numbers of medical personnel are inadequate. In these circumstances greater use should be made of para-medical personnel (Fendall, 1972).

The reports of the W.H.O. Regional Symposium for the Western Pacific (1969) described how to develop and maintain effective clinical services. It offers politicians, administrators, and clinicians guide lines on the best methods of distributing financial resources and personnel, and how to locate the patient in a developing country.

Dr. Marcolino Candau in his annual report for 1972 noted that venereal disease was spreading so rapidly that it threatened to become completely out of control. He advocated prompt action to avert this. The responsibility must lie with the clinicians to alert their administrators and politicians to the dangers. The various international organizations have their part to play. There is need for improved professional education about venereal diseases and more medical schools must be pressurized into commencing relevant research. Health education concerning venereal disease must be pursued with enthusiasm on an international front. There should be communication of epidemiological data and an increasing realization that the problem is an international one. Those countries with established control systems must be prepared to second trained personnel to advise their less fortunate neighbours. Attention should be paid to the standardization of drug preparations and more thought devoted to the elaboration of relatively cheap and efficient therapy suitable for developing countries. There has to be a realization that standards of medical care satisfactory for developed countries are not applicable to developing countries. Epidemiological treatment and screening programmes 
have a place in areas with very high infection rates but the use of these techniques has to be delineated.

Surely in this lies our best hope to 'locate' the patient.

\section{References}

American Social Health Association (1968) 'Today's V.D. Control Problem', American Social Health Association, New York

Brain, R. (1964) 'Doctors Past and Present', p. 253. Pitman, London

Brown, W. J. (1970) Ann. intern. Med., 72, 278

Dandoy, S., and McKenna, E. M. (1964) Publ. Hlth Rep. (Wash.), 79, 1015

DE AMorim, P. J. (1966) Hospital (Rio de faniero), 70, 1739

Euste, G. (1968) Dtsch. Gesundh., 23, 2489

Fendall, N. R. E. (1972) 'Auxiliaries in Health CareProgress in Developing Countries'. Johns Hopkins, Baltimore

FORER, R. (1965) Publ. Hlth Rep. (Wash.), 80, 1015

Guthe, T., and Willcox, R. R. (1971) Roy. Soc. Hlth F., 91, 122

HARRIS, J. R. W., MCCANN, J. S., and MAHONY, J. D. H. (1973) Brit. F. vener. Dis., 49, 42

HART, M. (1971) F. Amer. med. Ass., 216, 1609

HeRmans, E. H., and DE Cock, P. (1965) Acta Leidensia, 33, 107

IDsøe, O., and GuTHE, T. (1967) Brit. f. vener. Dis., 43, 227
JEFFERISS, F. J. G. (1966) Ibid., 42, 46

JefrRies, D. J., James, W. H., JefreRiss, F. J. G., MACLEOD, K. G., and Willcox, R. R. (1973) Brit. med.F., 2, 455

Kite, E. De C., and Grimble, A. (1963) Brit. F. vener. Dis., 39, 173

LомноLт, G. (1968) Lakartidningen, 65, 2156

MCKenzIE-Pollock, J. S. (1970) Brit. F. vener. Dis., 46, 114

Mellone, O., and Pagenotto, J. (1965) Rev. Hosp. clin. Fac. Med. Univ. S. Paulo, 20, 165

MoRTon, R. S. (1972) 'Venereal Diseases', 2nd ed. Penguin, Harmondsworth, London

OwEn, R. L., and Hill, L. J. (1972) f. Amer. med. Ass., 220, 1315

Pariser, H., Farmer, A. D., and Marino, A. F. (1964) Sth. med. F., 57, 688

Report of the National Commission on Venereal DISEASES (1972) U.S. Dept. of Health, Education, and Welfare, Publication No. 72-8125

RowntreE, F. St. D. (1966) Brit. f. vener. Dis., 42, 246

StaRCK-Romanus, V. (1973) Ibid., 49, 163

WEBSTER, B. (1970) Ibid., 46, 156

W.H.O. (1969) Regional V.D. Seminar W.H.O./ Western Pacific R.O. 0144

Willcox, R. R. (1950) f. roy. Army med. Cps., 94, 126

- (1966) Brit. F. vener. Dis., 42, 225

- (1970) Brit. F. clin. Pract., 24, 97

- Jefreriss, F. J. G., and NAUGhTEN, E. M. (1966) Brit. F. vener. Dis., 42, 167 